\title{
Applicability of health promoting lifestyle profile-Il for postmenopausal women in Sri Lanka; a validation study
}

\author{
Nirmala Rathnayake $1^{1^{*}}$ D, Gayani Alwis², Janaka Lenora ${ }^{3}$ and Sarath Lekamwasam ${ }^{4}$
}

\begin{abstract}
Background and objective: Health Promoting Lifestyle Profile-II (HPLP-II), developed in the West, evaluates 52 health promoting behaviors (HPB) under six subscales. In this study we evaluated the applicability of HPLP-II to assess the HPB of postmenopausal women (PMW) conversant in the Sinhala language in Sri Lanka.

Methods: The Sinhala version of HPLP-II was adapted following standard methodology of cross cultural adaptation. It included forward and backward translations, review by an expert group, focus group discussion and pre-testing. It was self-administered among randomly selected healthy, Sinhalese, community-dwelling PMW $(n=245$, aged $55.9 \pm 3.4$ years), along with the Short Form 36 (SF-36) survey. The Sinhala version of HPLP-II was re-administered among a subsample $(n=105)$ after two weeks of first administration. Psychometric properties - reliability and validity, were evaluated.

Results: In the Sinhala version of HPLP-II, both internal consistency (Cronbach's alpha $=0.98$ ) and test-retest reliability (intra class correlation / ICC $=0.98,95 \% \mathrm{Cl}=0.97-0.99$ ) were high. Structural validity assessment with Factor analysis using Principal Component Analysis extracted seven factors explaining 80.65\% cumulative variance with few exceptions from the original version. Health responsibility (HR) and spiritual growth (SG) subscales of HPLP-II and physical and psychological health dimensions scores of SF-36 scores correlated significantly $(r>0.63, p<0.001)$ ensuring strong concurrent validity.
\end{abstract}

Conclusions: The Sinhala version of HPLP-II adapted by us is a tool with high reliability and validity.

Keywords: Cross cultural adaptation, Health promoting lifestyle profile-II, Psychometric properties, Postmenopausal women, Reliability, Sinhala version, Validity

\section{Background}

Health promotion is a fundamental strategy in healthcare that implies changes in behavior and the adoption of patterns that promote good health in order to improve the quality of life (QOL) of people [1]. As defined by the World Health Organization (WHO) Ottawa Charter for Health Promotion (1986), health promotion

\footnotetext{
* Correspondence: nirmala.priyanthi@gmail.com

'Department of Nursing, Faculty of Allied Health Sciences, University of Ruhuna, Galle, Sri Lanka

Full list of author information is available at the end of the article
}

is "the process of enabling people to increase control over and improve their health" [2].

Health professionals obligate to promote health at the individual, group, and community levels. To achieve the targets of health promotion activities, assessment of their existing practices on health promoting behaviors (HPB) and their strengths and weaknesses need to be identified [3]. HPB are major determinants of health and are used in disease prevention [4].

The Health Promoting Lifestyle Profile-II (HPLP-II) [5] is a revision of the HPLP developed by Walker et al.

(c) The Author(s). 2020 Open Access This article is licensed under a Creative Commons Attribution 4.0 International License, which permits use, sharing, adaptation, distribution and reproduction in any medium or format, as long as you give appropriate credit to the original author(s) and the source, provide a link to the Creative Commons licence, and indicate if changes were made. The images or other third party material in this article are included in the article's Creative Commons licence, unless indicated otherwise in a credit line to the material. If material is not included in the article's Creative Commons licence and your intended use is not permitted by statutory regulation or exceeds the permitted use, you will need to obtain permission directly from the copyright holder. To view a copy of this licence, visit http://creativecommons.org/licenses/by/4.0/. The Creative Commons Public Domain Dedication waiver (http://creativecommons.org/publicdomain/zero/1.0/) applies to the data made available in this article, unless otherwise stated in a credit line to the data. 
[6]. It measures health promoting lifestyles as HPB by focusing on self-initiated actions and perceptions that serve to maintain or enhance the level of wellness, selfactualization, and fulfillment of the individual. It is a 52item questionnaire composed of six subscales including health responsibility (HR), nutrition (N), physical activity (PA), stress management (SM), interpersonal relations (IR), and spiritual growth (SG).

The English version of HPLP-II has shown high internal consistency and test-retest reliability [5]. It has been translated into different languages including Spanish, Japanese, Arabic, Taiwanese, Turkish and Portuguese [7-12] and its validity and reliability have been verified.

Menopause is one of the most significant events in women's lives. The evaluation of lifestyle with HPB is important when considering certain conditions and diseases encountered by postmenopausal women (PMW). Health promotion is particularly important for PMW, since healthy behaviors such as regular exercises and stress management can effectively reduce the severity of health problems and discomforts associated with menopause.

Health promoting lifestyle is not constant and possibly varies depending on the context, culture and language [13]. That emphasizes the importance of cultural adaptation and test the validity and reliability of a specific instrument in the particular population.

The original HPLP-II has been widely used to measure healthy women's HPBs in many societies $[14,15]$. However, studies related to HPB in Sri Lanka are sparse and this could partly be due to the lack of a valid instrument to measure HPB. A reliable instrument for the measurement of healthy lifestyle is therefore a necessity for understanding and addressing the health promotion needs of the PMW in Sri Lanka. Therefore, this study attempted to evaluate the applicability of HPLP-II to measure the HPB of PMW conversant in the Sinhala language in Sri Lanka, with the cross cultural adaptation and evaluation of psychometric properties.

\section{Methods}

\section{Study design, setting and participants}

This validation study was conducted in the BopePoddala Medical Officer of Health $(\mathrm{MOH})$ area, Galle District, in Southern Sri Lanka. The study participants in both cross cultural adaptation and psychometric validation were healthy community dwelling PMW who attained menopause naturally with intact uterus. Those with severe medical and surgical conditions, mental illnesses, disabilities and impairments of musculoskeletal system, endocrine disorders (diabetes, thyroid etc.), women on hormone replacement therapy (HRT) and illiterate women were excluded. Postmenopausal status was determined based on self-reported menstrual history using the classification of Stages of Reproductive Aging Workshop (STRAW) [16] which is the cessation of menstruation within the previous 12 months after last menstruation.

\section{Cross cultural adaptation of HPLP-II to Sinhala language}

The standard guidelines described by Beaton et al. [17] were followed for the cross cultural adaptation of the Sinhala version of HPLP-II. Forward translation of the original English version of HPLP-II was done by two independent health professionals. Then the items were consolidated in to a single questionnaire. The synthesized version was back translated to English language by two another independent health professionals. Then a group of experts (a physician, a gynecologist, a physiologist, an anatomist, a nursing academic and, forward and backward translators) independently reviewed all the versions of HPLP-II and a pre-final Sinhala version was decided ensuring its content validity. The face validity of the pre-final version of HPLP-II was ensured by having a focus group discussion (FGD) with 10 PMW. Then it was pretested among 30 PMW selected from another geographical location. These two steps further ensure the clarity, understandability and naturalness of items [18].

\section{Administration of Sinhala version of HPLP-II}

The newly adopted Sinhala version of HPLP-II and the previously validated Sinhala version of the Short Form 36 (SF-36) survey $[19,20]$ were self-administered among 245 PMW selected from the university training area to evaluate its psychometric properties. These women were selected using the multistage cluster sampling technique. Out of the 18 Public Health Midwife divisions (smallest community health unit) of the Bope-Poddala $\mathrm{MOH}$ area, three were selected randomly which were sub-urban areas. Houses and the female householders aged beyond 40 years were identified using the electoral registers of the respective areas obtained from the Grama Niladari Officer (local community administrative authority) of each division. Women who got odd numbers when the houses were arranged in a single list were invited for the study (excluding the women who had exclusion criteria) until the required sample size was achieved.

For the sample size calculation, five respondents in to one variable ratio was used [21]. Sample size was calculated by multiplying the number of variables in the instrument ( 52 items) by five in order to achieve the best sample $(n=260)$. After adding $10 \%$ to compensate with the non-respondents and incomplete questionnaires, the final sample size was calculated as 286. Even though we invited 286 women, only 272 women participated and 
only 245 PMW completed all the items in the questionnaires (response rate was 90\%).

The HPLP-II asks respondents to indicate how often they adapt to HPB with 52 items (statements) listed under six subscales and answers are required to be given on a 4-point Likert scale (never, sometimes, often, and routinely). The Short Form Survey (SF-36) provides a subjective estimation of the individual's functional state and QOL in two main dimensions (physical and psychological) [19].

The SF-36 survey was used in this study assuming that lifestyle has a significant relationship with QOL meaning that good lifestyle practices improve the QOL [22, 23].

HPLP-II was re-administered among a randomly selected subgroup of PMW $(n=105) 2$ weeks after the first administration.

\section{Statistical analyses}

The socio-demographic characteristics of the study participants in psychometric validation step are presented as frequencies (percentages) or mean (SD). The testretest reliability was examined by intra-class correlation coefficient (ICC) comparing the overall HPLP-II scores in two consecutive evaluations. Factor analysis (FA) performed with principal component analysis (PCA) evaluated the structural validity of the Sinhala version of HPLP-II. The Kaiser-Meyer-Olkin (KMO), Bartlett's test of Sphericity statistics and correlation matrix were observed [24]. The percentage of variance explained by each component and number of Eigen values over one (Kaiser-Guttman rule) were identified [24]. Concurrent validity was evaluated by observing the Pearson correlation coefficients [24] between the HR subscale score of HPLP-II and physical health dimension score of SF-36, and between the SG subscale score of HPLP-II and psychological health dimension score of SF-36 survey. Statistical analysis was performed with SPSS 20.0 version and $P$ value $<0.05$ was considered as statistically significant.

\section{Ethical considerations}

Permission from the original authors was sought before commencement of the process and ethical clearance for the study was obtained from the Ethical Review Committee, Faculty of Medicine, University of Ruhuna. Written informed consent was obtained from each participant who wished to take part in the study before administering the questionnaires.

\section{Results}

\section{Characteristics of the participants}

Age of the subjects ranged from 47 to 64 years while age at menopause and time since menopause ranged from 40 to 59 years and 2 to 7 years, respectively (Table 1 ).
Sociodemographic characteristics of the participated Sinhalese PMW and mean (SD) of subscale and overall HPB scores are presented in Table 1.

\section{Psychometric properties of Sinhala version of HPLP-II}

Internal consistency and reliability Sinhala version of HPLP-II showed a high internal consistency with global Cronbach's alpha of 0.98, and six subscales: HR 0.95, N 0.91, PA 0.91, IR 0.90, SM 0.88 and SG 0.91 respectively. The test-retest reliability measured with ICC was 0.98 (95\% CI $=0.97-0.99)$.

Structural validity FA using PCA was performed. The correlation matrix revealed the presence of many coefficients $>0.3$ (data not shown) while the KMO value was 0.89 , and Bartlett's Test of Sphericity reached statistical significance $(p<0.001)$ supporting the factorability of the correlation matrix and indicating the adequacy of sample size. PCA revealed the presence of seven factors with Eigen value exceeding one, explaining cumulative variance of $80.65 \%$ with varimax rotation in the rotated component matrix (each factor one to seven represent variances of 53.73, 7.71, 5.42, 4.78, 3.42, 3.08 and 2.49\%). All 52 items in the Sinhala version of HPLP-II were representative of a component as the coefficient loading of all items was $\geq 0.40$.

Factor 1 included a combination of items in all six domains (17 items), Factor 2 included items in the SM, IR and SG subscales (7 items), Factor 3 included items in the SG, IR and HR subscales (7 items), Factor 4 included items in the PA, N and SM subscales (6 items), Factor 5 included items in the SM, SG, IR and HR subscales (6 items), Factor 6 included items in the IR, N, PA and HR (6 items), and Factor 7 included only three items that were in the $\mathrm{N}$ and PA subscales (data not shown in tables).

Factors one to seven extracted in this analysis, showed satisfactory internal consistency; (Cronbach's alpha values) and item total correlations. The Cronbach's alpha for item 1 to 7 were $0.97,0.92,0.93,0.93,0.87$, 0.92 and 0.82 respectively. The item-total correlations for item 1 to 7 were $0.64-0.91,0.65-0.88,0.74-0.85$, $0.52-0.77, \quad 0.71-0.82, \quad 0.71-0.82$ and $0.68-0.68$ respectively.

Concurrent validity The Pearson correlation coefficient observed between the HR score of HPLP-II and physical health dimension score of SF- 36 and SG score of HPLP-II and psychological health dimension score of SF-36 were high that indicated strong concurrent validity of the HPLP-II (Table 2). 
Table 1 Basic characteristics of the study participants $(n=245)$

\begin{tabular}{|c|c|c|}
\hline Characteristic & Sub category & Mean (SD) or Frequency (\%) \\
\hline \multicolumn{3}{|l|}{ Sociodemographic Characteristics } \\
\hline Age (years) & & $55.9(3.4)$ \\
\hline Age at menopause (years) & & $50.4(2.9)$ \\
\hline time since menopause (years) & & $5.6(1.9)$ \\
\hline \multirow[t]{2}{*}{ Employment status } & Employed & $59(24.1)$ \\
\hline & Non employed or retired & $186(75.9)$ \\
\hline \multirow[t]{4}{*}{ Civil status } & Married & $208(84.8)$ \\
\hline & Single & $16(6.5)$ \\
\hline & Widowed & $13(5.3)$ \\
\hline & Divorced & $8(3.2)$ \\
\hline \multirow[t]{3}{*}{ Living companion } & With husband and children & $134(54.6)$ \\
\hline & With Husband or Children & $86(35.1)$ \\
\hline & Alone or living with others & $25(10.2)$ \\
\hline \multirow[t]{3}{*}{ Education status } & Primary education & $105(42.8)$ \\
\hline & Secondary education & $71(29.0)$ \\
\hline & Upper secondary education, degree or diploma & $69(28.1)$ \\
\hline \multirow[t]{4}{*}{ Monthly income } & $<10,000$ LKR & $90(36.7)$ \\
\hline & $10,000-20,000$ LKR & $95(38.8)$ \\
\hline & $20,000-50,000$ LKR & $50(20.4)$ \\
\hline & $>50,000$ LKR & $10(4.1)$ \\
\hline \multicolumn{3}{|l|}{ HPB scores } \\
\hline Health Responsibility & & $17.10(5.93)$ \\
\hline Nutrition & & $19.10(4.99)$ \\
\hline Physical Activity & & $12.50(4.35)$ \\
\hline Stress Management & & $16.19(4.01)$ \\
\hline Spiritual Growth & & $20.42(4.87)$ \\
\hline Interpersonal Relations & & $20.23(4.54)$ \\
\hline Overall HPB score & & $105.64(26.61)$ \\
\hline
\end{tabular}

$\mathrm{LKR}=$ Sri Lankan rupees $(180 \mathrm{LKR}=1 \mathrm{USD}), H P B=$ Health promoting behaviors Living with others include; parents, siblings, friends or other relatives

\section{Discussion}

The current study examined the ability of HPLP-II in evaluating the HPB of Sinhala speaking PMW in Sri Lanka. We observed that HPLP-II adapted to the Sinhala language has satisfactory reliability and validity indicating that the instrument is suitable for this purpose.

Table 2 Correlation between HPLP-II scores and SF-36 scores

\begin{tabular}{lll}
\hline HPLP-II & SF-36 survey & \\
\cline { 2 - 3 } & Physical health dimension & Psychological health dimension \\
\hline HR score & $0.75^{\mathrm{a}}$ & - \\
SG score & - & $0.63^{\mathrm{a}}$
\end{tabular}

${ }^{a}$ Correlation is significant at $<0.001$ level HPLP-II = health promoting lifestyle profile-II, SF-36 = short form 36 survey, $\mathrm{HR}=$ health responsibility, $\mathrm{SG}=$ spiritual growth
The items in the questionnaire were culturally adapted without compromising the original meaning but additional explanations relevant to the Sri Lankan context, such as, types of PA and food items were provided. Focus group discussions and pre-test analysis confirmed that the two-way translation process was successful in developing the Sinhala version of the HPLP-II and respondents found it easy to understand and complete.

The internal consistency and the reliability were higher in the questionnaire indicating its stability and repeatability. Structural validity evaluation in FA with PCA extracted seven factors that were different from the original factor structure of HPLP-II. These seven factors however explained a high variance of $80.65 \%$. Further, concurrent validity of the questionnaire was tested against the SF-36 questionnaire, assuming that PMW 
who adhere to HPB have higher overall QOL. This study showed similarities of reliability and validity with previous studies while the factor structure differs in several aspects.

Internal consistency measured with Cronbach's alpha of the entire questionnaire and subscales were concordant and at times exceeded the values observed elsewhere including the Turkish version [12], Taiwanese version [11], Spanish version [7] and Portuguese version [10]. Testretest reliability was higher when compared with the original study [5], Iranian version [25], Taiwanese version [11], Spanish version [7] and Portuguese version [10].

In previous analyses, six main factors have appeared in the Iranian version [25], Taiwanese version [11], Spanish version [7] and Portuguese version [10]. However, in the Turkish version, 14 factors (explaining $61 \%$ of the variance) were found but the Scree plot graphic showed five factors, explaining $41 \%$ of the variance [12].

The correlation between the HPLP-II and QOL score is higher than that was observed in the Taiwanese version [11] in concurrent validity evaluation. This is the only study focused the evaluation of concurrent validity of HPLP-II.

The separation of items in the factor extraction in the current study can be due to many reasons including culture difference in attitudes and practices. Western women may interpret concepts such as "PA" as regimens describing jogging, lifting weights or swimming, whereas in Sri Lanka, PA is more likely to describe the day-today routine work. Furthermore, application of Kaiser's criterion when more than 50 variables are involved also lead to the extraction of too many factors [26]. However, we observed that extracted factors had higher internal consistencies indicating that this factor extraction is more meaningful to the Sinhala language.

The higher correlation observed between HPLP-II and SF-36 scores in the current study could partly be due to the reference tool used to assess the concurrent validity. We used the SF-36 survey and the Taiwan study had used WHO-BREEF questionnaire. The scarcity of studies to evaluate the concurrent validity would be due to the absence of a proper tool to evaluate the correspondence of HPB. However, it is obvious that HPB increase or decrease the QOL, and therefore, we did not see any limitation in our approach in evaluating the concurrent validity. Illiterate women were not included in the study since the questionnaire was self-administered and the large number of items in the questionnaire could have influenced the quality of data. These are the few limitations of the current study. This validated questionnaire would help to collect better quality data in existing HPB of individuals. It increases the credibility of data related to the health promotion in all the individuals fluent in Sinhala language. Health promotion activities could be initiated based on the findings of this validated questionnaire.

Since Sri Lanka has a multi-ethnic community it is important to adapt a Tamil version of HPLP-II to suit the Tamil speaking community. It is also important to use a shortened version of this tool in future studies. Furthermore, confirmatory FA should be focused in those future studies.

\section{Conclusion}

This study demonstrated linguistic and cultural acceptance and satisfactory psychometric properties; reliability and validity in the Sinhala version of HPLP-II.

\section{Abbreviations}

HPLP-II: Health Promoting Lifestyle Profile-II; HPB: Health Promoting Behaviors; PMW: Postmenopausal Women; SF-36: Short Form 36 survey; ICC: Intra Class Correlation; QOL: Quality of Life; HR: Health Responsibility; N: Nutrition; PA: Physical Activity; SM: Stress Management; IR: Interpersonal Relations; SG: Spiritual Growth; MOH: Medical Officer of Health; HRT: Hormone Replacement Therapy; STRAW: Stages of Reproductive Aging Workshop; FA: Factor Analysis; PCA: Principle Component Analysis; KMO: Kaiser-Meyer-Olkin

\section{Acknowledgements}

The authors wish to express sincere gratitude to the professionals involved in cross cultural adaptation process; Dr. Iresha Mampitiya, Ms. Nirmala Gamage, Ms. Harshani Dias, Ms. Pramudika Kariyawasam, Ms. Hemamali Madushanthi and all the participants of the study. Further, Mrs. Chithra Ranasinghe, Retired WHO staff member is also acknowledged for her support on English language editing.

\section{Authors' contributions}

All authors involved in conception of the study and design of the work, NR involved in data collection, data analysis and initial drafting of the manuscript, GA and $J$ involved in interpretation of analyzed data, critically reviewing of the manuscript. SL contributed to interpretation of analyzed data and critically reviewing the manuscript for important intellectual content. All authors read and approved the final version of the manuscript.

\section{Funding}

Faculty Research Grant (2014-2015), Faculty of Medicine, University of Ruhuna, Sri Lanka and National Research Council (NRC 15-023), Sri Lanka, funds mainly involved with the collection of data.

\section{Availability of data and materials}

The datasets used and/or analyzed during the current study are available from the corresponding author on reasonable request.

\section{Ethics approval and consent to participate}

Ethical clearance for the study was obtained from the ethical review committee, Faculty of Medicine, University of Ruhuna, Sri Lanka. Informed written consent was obtained from each participant prior to the commencement of the study.

\section{Consent for publication}

Not applicable.

\section{Competing interests}

The authors declare that they have no competing interests.

\section{Author details}

${ }^{1}$ Department of Nursing, Faculty of Allied Health Sciences, University of Ruhuna, Galle, Sri Lanka. ²Department of Anatomy, Faculty of Medicine, University of Ruhuna, Galle, Sri Lanka. ${ }^{3}$ Department of Physiology, Faculty of Medicine, University of Ruhuna, Galle, Sri Lanka. ${ }^{4}$ Population Health Research 
Centre, Department of Medicine, Faculty of Medicine, University of Ruhuna, Galle, Sri Lanka.

Received: 2 December 2019 Accepted: 22 April 2020

Published online: 06 May 2020

\section{References}

1. Kumar S, Preetha G. Health promotion: an effective tool for global health. Indian journal of community medicine: official publication of Indian Association of Preventive \& Social Medicine. 2012;37(1):5. Available from; https://www.ncbi.nlm.nih.gov/pmc/articles/PMC3326808/. Accessed 10 Jan 2019.

2. Green LW, Raeburn JM. Health promotion. What is it? What will it become? Health Promotion International. 1988;3(2):151-9. Available from; https:// academic.oup.com/heapro/article-abstract/3/2/151/567755? redirectedFrom= fulltext. Accessed 10 Jan 2019.

3. Pender N, Murdaugh C, Parsons M. Individual models to promote health behavior. Health Promotion Nurs Pract. 2006:35-73.

4. Mo PK, Winnie WM. The influence of health promoting practices on the quality of life of community adults in Hong Kong. Social indicators research 2010;95(3):503-17. Available from; https://eric.ed.gov/?id=EJ873824. Accessed 10 Jan 2019.

5. Walker S, Hill-Polerecky DM. Psychometric evaluation of health promoting lifestyle profile II. Lincoln: Unpublished manuscript, University of Nebraska Medical Center, College of Nursing; 1997. Available from; https://deepblue. lib.umich.edu/bitstream/handle/2027.42/85349/HPLP_IIDimensions. pdf? sequence $=2$. Accessed 10 Jan 2019.

6. Walker SN, Sechrist KR, Pender NJ. Health-promoting lifestyle profile: development and psychometric characteristics. Nursing research. 1987. Available from; https://www.ncbi.nlm.nih.gov/pubmed/3644262. Accessed 10 Jan 2019.

7. Walker SN, Kerr MJ, Pender NJ, et al. A Spanish language version of the HealthPromoting Lifestyle Profile. Nurs Res. 1990;39(5):268-73. Available from; https:// www.ncbi.nlm.nih.gov/pubmed/2399130. Accessed 10 Jan 2019.

8. Wei C-N, Harada K, Ueda K, et al. Assessment of health-promoting lifestyle profile in Japanese university students. Environ Health Prev Med. 2012;17(3): 222. Available from; https://www.ncbi.n/m.nih.gov/pubmed/21987366. Accessed 10 Jan 2019.

9. Haddad LG, Al-Ma'aitah RM, Cameron SJ, et al: An Arabic language version of the health promotion lifestyle profile. Public Health Nurs. 1998;15(2):7481. Available from; https://www.ncbi.nlm.nih.gov/pubmed/9564211. Accessed 10 Jan 2019

10. Sousa P, Gaspar P, Vaz DC, et al. Measuring Health-Promoting Behaviors: Cross-Cultural Validation of the $\mathrm{H}$ ealth-P romoting Lifestyle Profile-II. Int J Nurs Knowl. 2015;26(2):54-61. Available from; https://www.ncbi.nlm.nih.gov/ pubmed/25389054. Accessed 10 Jan 2019

11. Meihan L, Chung-Ngok W. Validation of the psychometric properties of the health-promoting lifestyle profile in a sample of Taiwanese women. Qual Life Res. 2011;20(4):523-8. Available from; https://www.ncbi.nlm.nih.gov/ pmc/articles/PMC3075398/. Accessed 10 Jan 2019.

12. Pinar R, Celik R, Bahcecik N. Reliability and construct validity of the HealthPromoting Lifestyle Profile II in an adult Turkish population. Nurs Res. 2009; 58(3):184-93. Available from; https://www.ncbi.nlm.nih.gov/pubmed/1944 8522. Accessed 10 Jan 2019

13. Pérez-Fortis A, Ulla Diez SM, Padilla JL. Psychometric properties of the Spanish version of the health-promoting lifestyle profile II. Res Nurs health. 2012;35(3):301-13. Available from; https://europepmc.org/abstract/ med/22434744. Accessed 10 Jan 2019.

14. Mirghafourvand M, Baheiraei A, Nedjat S, et al. A population-based study of health-promoting behaviors and their predictors in Iranian women of reproductive age. Health Promot Int. 2014;30(3):586-94. Available from; https://www.ncbi.nlm.nih.gov/pubmed/24395956. Accessed 10 Jan 2019

15. Duffy ME. Determinants of reported health promotion behaviors in employed Mexican American women. Health Care Women Int. 1997;18(2): 149-63. Available from; https://www.ncbi.nlm.nih.gov/pubmed/9119791. Accessed 10 Jan 2019.

16. Harlow SD, Gass M, Hall JE, et al. Executive summary of the Stages of Reproductive Aging Workshop + 10: addressing the unfinished agenda of staging reproductive aging. Fertil Steril. 2012:97(4):843-51. Available from; https://www.ncbi.nlm.nih.gov/pubmed/22341880. Accessed 10 Jan 2019.
17. Beaton DE, Bombardier C, Guillemin F, et al. Guidelines for the process of cross-cultural adaptation of self-report measures. Spine. 2000;25(24):3186-91. Available from; https://www.ncbi.nlm.nih.gov/pubmed/11124735. Accessed 10 Jan 2019.

18. Rathnayake N, Lenora J, Alwis G, et al. Cross cultural adaptation and analysis of psychometric properties of Sinhala version of Menopause Rating Scale. Health Qual Life Outcome. 2018;16(1):161. Available from; https://doi.org/10. 1186/s12955-018-0977-9. Accessed 10 Jan 2019.

19. Ware JE, Jr. SF-36 health survey update. Spine. 2000;25(24):3130-39. Available from; https://www.ncbi.nlm.nih.gov/pubmed/11124729. Accessed 10 Jan 2019.

20. Gunawardena NS, Seneviratne SRD, Atauda T. An approach to validation of a multi-dimensional tool. J Coll Community Physicians Sri Lanka. 2003;8:18-26.

21. Tabachnick BG, Fidell LS. Using multivariate statistics: Harper Collins college publishers, New York; 1996.

22. Huang H-C, Chou C-T, Lin K-C, et al. The relationships between disability level, health-promoting lifestyle, and quality of life in outpatients with systemic lupus erythematosus. J Nurs Res. 2007;15(1):21-32. Available from; https://www.ncbi.nlm.nih.gov/pubmed/17370230. Accessed 10 Jan 2019.

23. Rakhshani T, Shojaiezadeh D, Lankarani KB, et al. The association of healthpromoting lifestyle with quality of life among the Iranian elderly. I ranian Red Crescent Medical Journal. 2014;16(9). Available from; https:/www.ncbi. nIm.nih.gov/pubmed/25593729. Accessed 10 Jan 2019.

24. Arafat SMY. Cross cutural adaptation \& psychometric validation of instruments: step-wise description International journal of psychiatry. 2016; 1 (1):1-4. Available from; http://www.opastonline.com/wp-content/uploads/2 016/07/cross-cultural-adaptation-psychometric\%20validation-of-instrumentsstep-wise-description-ijp-16-001.pdf. Accessed 10 Nov 2017.

25. Tanjani PT, Azadbakht M, Garmaroudi G, et al. Validity and reliability of health promoting lifestyle profile II in the Iranian elderly. Int J Prev Med. 2016;7. Available from; https://www.ncbi.nlm.nih.gov/pubmed/27280010. Accessed 10 Jan 2019

26. Norman GR, Streiner DL. PDQ statistics, vol. 1: PMPH-USA; 2003.

\section{Publisher's Note}

Springer Nature remains neutral with regard to jurisdictional claims in published maps and institutional affiliations.

\section{Ready to submit your research? Choose BMC and benefit from:}

- fast, convenient online submission

- thorough peer review by experienced researchers in your field

- rapid publication on acceptance

- support for research data, including large and complex data types

- gold Open Access which fosters wider collaboration and increased citations

- maximum visibility for your research: over $100 \mathrm{M}$ website views per year

At BMC, research is always in progress.

Learn more biomedcentral.com/submissions 